\title{
INSTITUTIONAL MODERNIZATION OF THE GLOBAL ECONOMY
}

\author{
Maryna Radieva'
}

\begin{abstract}
The aim of the research is the improvement of the concept of the institutional structure of the economy in the conditions of corporatization on the basis of researching the international experience of development of stable basic institutions of the institutional environment. Methodology. The methodological basis of the study is the provisions of the institutional theory using the analysis methodology "institutional matrix". Historical-logical and dialectical methods were also used to study the contradictions in the processes of formation and development of the international institutional environment. Results. Institutional dynamics is the result of the functioning of a global international and specific national institutional environment, a formed subclass, ideological, economic, nationalhistorical factors, essential values, ethnic characteristics and characteristics of the nation's mentality that are formed under the influence of long-term cultural influence and as a result of social interaction. Forced creation of new structures and private-property relations, supported by a massive import of market institutions in the absence of adequate national formal institutions and informal corporate culture, has led to non-fulfilment of contracts, a low business culture, opportunistic behaviour and informal contracts. In the process of introducing economic agents to institutional changes, invent quasi-market mechanisms: the predatory use of all types of resources, barter, income concealment, shadow schemes of tax evasion, offshore, "under-the-counter" wages, raiding, corruption at all levels of government, wide scale and versatility opportunism, violation of contracts, and the consumption of fixed assets. These manifestations intensified the structural deformations of the market and the transformational risks of the national economy. It is revealed that the development of the corporate economy on an innovative basis under the influence of globalization and monopolization, changes the individual institutions of the basic $Y$ - and $\mathrm{X}$ - matrices. A new concept is proposed for constructing an institutional matrix using two principles of economic distribution: the market economy and the distribution economy; on the corporate and individual sectors of the economy. Two types of institutional matrices - corporate K-matrices and individual I-matrices - function in basic $\mathrm{X}$ - and Y-matrices, dividing each of the economies into two unequal parts (in terms of effectiveness, influence and significance of consequences). Corporate transformations turn individual complementary institutions of the market economy into the basic institutions of the corporate part of the Y-economy. Continuing institutional displacement requires finding the optimal balance between basic and complementary institutions in the corporate and unincorporated sectors of the Ukrainian economy, based on the use of specific institutional matrices, which will allow for institutional construction and minimize the social costs of the country's evolutionary development. The concept of the institutional-matrix structure of the economy has been improved taking into account the modern tendencies of corporatization. The economy is defined as a set of basic institutions of two types of matrices that are unequal in efficiency, influence and significance of consequences: the corporate K-matrix and the individual private ownership of the I-matrix. Practical implications. The distribution of the economy into the corporate and individualprivate ownership sectors was the result of institutional transformations of certain complementary institutions of the market economy into basic ones, reveals the ways and sustainable mechanisms of institutionalization for the effective transformation of local institutional environments. The creation of an effective institutional environment will be ensured through the cultivation of institutional changes. Value/originality. The ongoing institutional displacement due to the intensification of the processes of monopolization and internationalization requires the search for an optimal balance of basic and complementary institutions in the corporate and unincorporated sectors of the Ukrainian economy, based on the use of specific institutional matrices, which will allow for institutional construction and minimize the social costs of the country's evolutionary development.
\end{abstract}

Key words: basic institute, complementary institution, institutional matrix, institutional environment.

JEL Classification: D02, D23, E02, E71

\footnotetext{
Corresponding author:

${ }^{1}$ Melitopol Institute of Public and Municipal Administration of the Classic Private University, Ukraine.

E-mail: ra_va@ukr.net
} 


\section{Introduction}

In the modern global economy, the renovation of the institutional environment is almost uncontrollable. Institutional biases continue, contrary to popular belief about the "specific, but formed", institutional environment. The vector of institutional transformations of the global and national economy is changing, the rethinking of which is yet to come.

In the Ukrainian economy, a number of factors have developed, actively opposing the processes of establishing an effective institutional environment. The unfavourable development of the institutional environment has resulted in inadequately formed labour, capital, land markets, the economy's orientation toward administrative and distributive relations, inefficiency and injustice of property relations, the information closeness of the capital market, high transaction costs, high uncertainty, and the reduced investment attractiveness of Ukrainian companies.

Features of institutional development are impossible to borrow the management mechanisms used in developed countries with historically created formal and informal institutions. Reforming of the borrowed Western institutions led to unpredictable and negative consequences.

Specific political, ideological, and economic factors in the development of the Ukrainian economy require new approaches to the institutionalization of the country. The task of finding new approaches is reducing the negative impact and negative consequences in the process of restructuring state and non-state Ukrainian institutions.

The fundamental feature of the Ukrainian institutional environment is the complexity or even the impossibility of establishing Western institutions since institutional changes have a clearly expressed national specificity. The import of institutions with subsequent legal fixing, which in most cases ensures the institutionalization of the economy, is not always effective, and sometimes impossible. There is a need for their cultivation and selfdevelopment in the national institutional environment.

\section{Institutional matrices of the global economy}

Stable basicinstitutions of the institutional environment form an "institutional matrix" (North, 1990). The institutional matrix is understood as a set of basic institutions that form a framework for retaining the main subsystems of the environment, ensuring reproduction and institutional dynamics. The basic institutions reflect the deep features of social structures that determine the number of possible trajectories for the further development of an institutional society. The nature of the basic dominant institutions determines the nature of the institutional development of the economic system. Basic economic institutions fix ways of the interaction of economic entities with the institutional environment for achieving the best result, that is, institutionalizes the forms of economic integration of society.

Recently, the concept that a variety of institutional complexes is based on one of two matrices has become widespread. The X-matrix is inherent in the states of the eastern part of the world - Russia, most countries in Asia and Latin America; B-matrix is typical for countries of Western Europe and the United States.

Institutional matrices in the economy. Social institutions exist independently of the cultural context, outside civilizational forms. Both matrices consist of three groups of basic institutions: economic, political, and ideological. Each institution of one matrix is opposed to the corresponding institution of the other matrix. The institutional matrix ensures the historical stability of institutions with respect to external and internal influences. In society, the principle of the dominance of the basic institutions of the matrix operates, which means the dominance of all three types of institutions of this matrix. The institutional matrix is characterized by integrity, that is, the dominance of one of the basic institutions of the matrix leads primacy and the other two types of institutions in society. At the same time, complementary institutions can operate with an alternative matrix, but they have an auxiliary character. The basic institutions establish restrictions on the operation of complementary institutions (Kirdina, 2017).

Basic institutes are historical invariants that retain their nature, provide a "blocking effect" for selfmaintenance of the matrix structure (Donchenko, 2013). Complementary institutions ensure the stability and balance of the socio-economic system. Basic institutions are characterized by unmanageability and can lead society to chaos and crisis. Targeted actions of the state and government are directed to the development of complementary institutions for balancing a particular public sphere. The balanced ratio of basic and complementary institutions becomes the task of managing the institutional structure.

The economic structure of society is the result of a combination of production relations. Objective prerequisites for the creation of an institutional economic system are the peculiarities of material conditions and technologies, that is, the technological basis of institutional changes (North, 1990; Schumpeter, 1989; Kirdina, 2017). Analysis of institutional dynamics based on the introduction of new technologies reveals the dialectics of interaction between institutions and individuals. Institutes are formed in a specific institutional environment, respectively, institutions determine the purposeful direction of human activity.

Economic institutions that become the most effective means of organizing a national economy are formed in concrete material conditions, determined by them and do not exist outside these provisions. The basis for the development of the matrix becomes such characteristic of the material and technological environment of the 
country as communal (or uncommunicated), that is, the use of the environment as a single indivisible system, parts of which can't be separated without the threat of disintegration of the environment. The communality of the material and technological environment provides for the continuity of the links between the elements. The properties of the communality (non-communality) of the environment do not change over time. The material and technological environment determines institutional technologies and enhances the character of the manifestations of basic institutions (Kirdina, 2017). The type of property - general or private - is associated with the amenities and costs of specification and protection of property rights.

Historically, the individual properties of the material medium of the Ukrainian economy determined its "communality" preventing the consolidation of private property rights: particularly the economic landscape, unfavourable climate, short-term field work, specific cultivation techniques, the use of slash-and-burn agriculture, low temperature, low crop yields and the consequent need to expand the acreage, permanent transfer to another land, the market unprofitable.

\section{Institutional-matrix concept of modern economy}

The use of the specifics of institutional matrices allows for the implementation of institutional construction and minimizing the social costs of the country's evolutionary development. However, historically, the mental orientation of institutional dynamics is conditioned and the recognition of the economy of the aggregate of basic and complementary institutions in accordance with the type of matrix does not abolish the processes of modernization of the institutional environment. The unsuccessful institutional transformations of Ukrainian society indicate, rather, the ill-considered, rather than the hopelessness of institutional transformations. The success of further reforms is related to the restoration of the effective functioning of the basic $\mathrm{X}$-type institutions, the substantial modernization of their forms, the continuation of the search and the institutional development of effective complementary institutions.

However, let's believe that the division of the world into the $\mathrm{X}$ - and Y-type economies does not correspond to the current trends of globalization, corporatization, and monopolization of the world economy. The corporate economy is gradually changing the individual institutions of the basic B-matrix of countries with market economies of the West and the US and affects the vector of development of the X-matrix institutions. The introduction of innovations allows the corporation to overcome the inertia of the permanent institutions and change them.

Corporationsaresubjects of the marketeconomy-have a hierarchical structure corresponding to the institution of coordination of the opposite matrix. A corporation is an aggregate of enterprises or industries operating on the basis of consolidation and forms a cooperative institution. The need to increase the capitalization of corporations led to a special institution of jointstock (not common and private) property. It is almost universally recognized that the goal of the corporation (and some scientists consider the corporation itself to be an independent organism) is not the maximization of profits, but the opportunities for further growth.

Let's try to clarify the composition of the main institutions of modern economic systems, distributing the economy to the corporate and individual sectors, by a similar distribution to the planning and market economy proposed by Galbraith (1952).

Two types of institutional matrices - corporate $\mathrm{K}$-matrices and individual I-matrices - function in basic $\mathrm{X}$ and $\mathrm{Y}$ matrices, dividing each of the economies into two unequal parts (in terms of effectiveness, influence and significance of consequences). Corporate transformations transform the complementary institutions of the market economy, such as coordination, cooperation, and collectivism, into the basic institutions of the corporate part of the B-economy (Figure 1).

By the method of purposeful observation, theoretical generalization and empirical analysis, let's have confirmed the existence of several institutions that form the basis of the institutional matrix of the corporate environment. This sample is a collection of individual institutions of the X- and Y-matrices, which become the basic institutions of the corporate economy. Each element of the institutional environment is a set of basic and complementary institutions that are specific to this level of the institutional environment.

The institutional environment is formed under the influence of political, ideological, economic, nationalhistorical factors and becomes a reflection of the specifics of the development of these factors.

The existence of a relationship between the ownership structure and the processes of democratization of society and the economy confirms the analysis of ownership structure in developed countries. Political structure - authoritarian or democratic - forms the dominant nature of governance in corporations. In countries with a developed economy and democratic political structure, corporations with a large number of owners prevail, in countries with an authoritarian political order, corporations with a dominant owner (family or state) are formed.

A significant concentration of corporate assets in the hands of several owners can significantly influence the dynamics and results of political reforms and democratic reforms, preventing the formation of a new institutional environment. The inadequacy, inconsistency, and ineffectiveness of the institutional framework lead to disagreements between corporate and social goals, generates social conflicts (Radieva, 2018). 


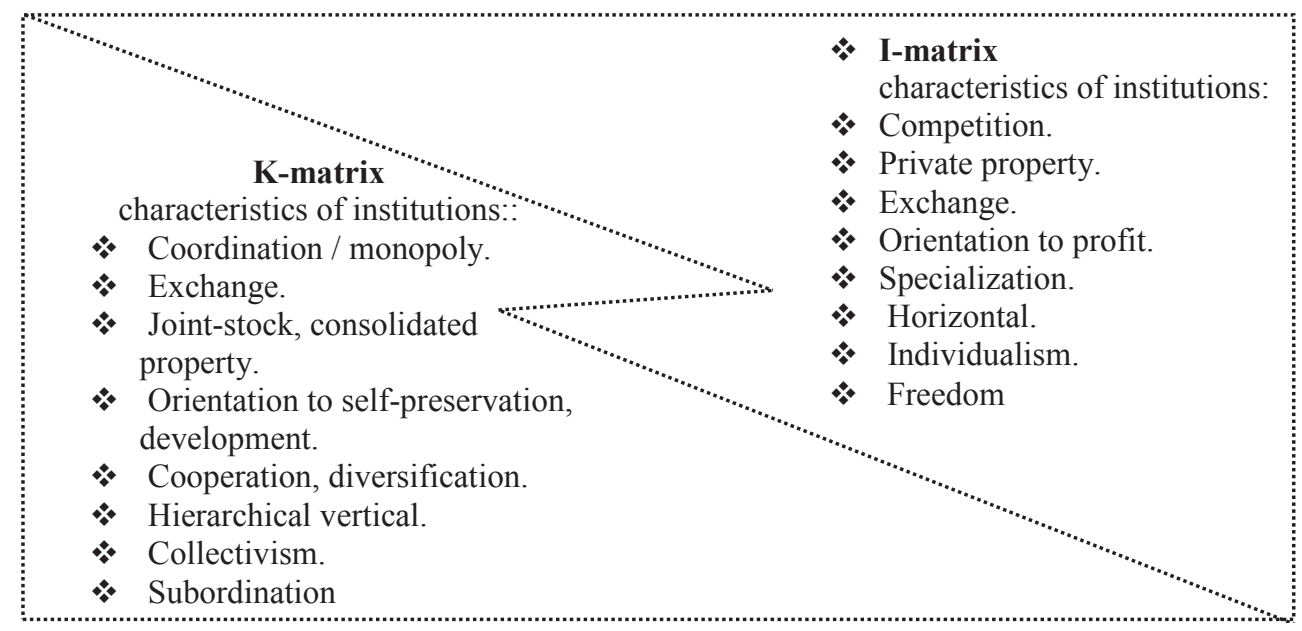

Figure 1. Institutional-matrix concept of modern economy

The scenario of the development of society depends on the idea - an informal institution, under the influence of which the development of a new society is taking place. The idea is transformed into the priority goals of society. This explains the features of the law of the unity of productive forces and production relations in the Ukrainian economy. The problem of the lag in the development of production relations from the development of productive forces as a result of the action of many factors, primarily technological, can be solved in two ways: first, the production relations develop to the level of productive forces; second, production forces are destroyed to the level of production relations. If the idea provides for the selection and development of institutions, tightening production relations to productive forces, society develops on its own, and more progressive society is born. The national Ukrainian idea was formed and continues to degenerate in a specific institutional environment, reflecting the pathologies of the democratization of society and affects the development of the economy's democratization.

The goals of the dominant groups in the structure of the share capital distribution are determined by the goals of the given society, formed by the political and economic elite. The structure of property distribution among certain groups of owners becomes a reflection of the idea, transformed into priority goals of society. Let's suppose that there is also an inverse relationship: the goals of society are determined by the goals of the dominant corporate owners, who are the political and economic elite of this society. The national idea is reborn as a result of the transformation of property relations. It is likely that the dominant owners of corporate rights, which are the political and economic elite of society, will determine the goals of this society. Imposing the goals of the dominant groups to the whole of society can be disastrous for the system, destroying it through political, social, and economic crises. The state's goal is introducing an institutional control and preventing attempts to subordinate the interests of society to the interests of economically closed groups with antisocial goals.

Obstacles to modern market reforms are conditioned by the specifics of society, which has caused the spread of the civilizational and socio-cultural paradigm of the development of society. Part of the failure of reform can be explained by the socio-cultural characteristics of the country. The sociocultural system is characterized by a combination of essential values and ethnic characteristics of social actors, formed under the influence of long-term cultural influence and as a result of human interaction. Directions of the transformation of society are connected with sociocultural models, determined by the priority form of behaviour of subjects: societies with traditionalist values demonstrate the priority of prescribed norms and rules of conduct; societies with liberal values provide opportunities for client-oriented innovative actions. The way of traditionalist societies generates the stability of totalitarian structures, alienation of a person from public life, low innovative activity. The socio-cultural approach complements the analysis of institutional transformations by methods based on the revealed patterns of historical formation and stability of sociovalue structures, the diversity of manifestations of the main socio-economic processes in different cultural and historical contexts, but not without some limitations.

The use of a sociocultural approach to the analysis of economic transformations makes it possible to reveal the ways and stable mechanisms of the institutionalization of a new social and economic system. Societal transformation (transformation of the macrolevel) determines the pace and ways of the transformation of local institutional environments.

Mentality can be presented as a stable institution, containing information on national economic, political, and ideological features. Mentality forms the core of culture, organizes the activities of individuals in accordance with generally accepted behaviour, values, 
perceptions, attitudes, customs, national traditions, morality. National mentality and stereotypes of national behaviour themselves organize the activities of individuals. The Ukrainian mentality is formed under the influence of two opposite tendencies of Ukraine's development as the hetman's republic and part of the imperial state.

Let's describe some characteristic features of the national mentality, become essential characteristics of the Ukrainian institutional environment, and the factors of their formation. To them let's refer collectivism, motivation to achieve short-term goals, ineffective incentives for development, the Orthodox spiritual priority over the worldly.

Confessional factors influenced the formation of the national mentality and the formation of the economic system. Religion is the most important factor in shaping the structure of society's values. It is reflected in the values of religious salvation, the directions of spiritual integration of different peoples and ethnic groups, forms of the interrelation between the spiritual and social structure, the nature of secular culture, determines the level of the society's final orientations.

Development offormsofinteraction, mutualassistance, and the formation of collectivist consciousness of the people contributed to the remoteness of the periphery from the centre and the features of economic activity. The lack of communication and transport for centuries enshrined the public's perception of the powerlessness of the central government.

\section{Characteristics of the institutional environment of the Ukrainian economy}

The specifics of the institutional environment determine the specifics of the economic system, which can have formal and informal components by the criterion of the vast majority of formal or informal institutions. The informal economy is the self-organization of economic agents, the principles of which are not institutionalized in formal rules.

Informal "rules of the game", not controlled by official institutions, extend to those relations between economic agents, excite households and the shadow economy. The development of the informal economy is wrong to associate only with the characteristics of the transitional period, but rather can be presented as a logical consequence of the peculiarities of the national mentality and ideology. The Ukrainian economy intuitively chose the path of development, the most consistent with the national mentality.

The factor of the informal economy development has become the traditionally negative attitude towards the bureaucracy, the perception of the state as an enemy, which can be deceived, robbed, broken promises. Even more, distanced people from the state violent state reforms. Institutional bias caused by Russian reformers -
Peter I, P. Stolypin, V. Lenin, M. Gorbachev - created fundamentally new formal institutions, pulling out broad masses of the population from the usual stable institutional arrangements. Violent changes had an extremely painful impact on the existence of society.

Another feature of the national environment was the redistributive nature of the economy (Polanyi, 1957) with subsequent transformation into the distribution economy (Bessonova, 2017).

Self-organization of non-market economic relations of the distributing economy is based on the mechanisms of redistribution, coexisting with market institutions on the principles of "dominance-compensatory". The geographic area forms a market or non-market type of institutional core, ensures effective coordination of local environments: natural-climatic, material-technological, national-demographic, cultural-religious. The theory of integral institutionalism justifies the invariance of the nature of the institutional core of each type of economy, while the institutional forms are changing in accordance with the peculiarities of the institutional platform.

Quasi-market mechanism of the distribution economy has the external features of a market economy, but it retains latent distribution content, pulling firms into the struggle for state resources. Corporations use influence on power structures to control competition. The functioning of new corporate forms and modern quasi-market institutions ensure the formation of a system of "liberal distribution". The main element of such a system will be state corporations with a vertically integrated structure, the complexes will be replaced hierarchically by hierarchies (Bessonova, 2017).

The revolutionary nature of historical and modern institutional transformations, accompanied by a sharp change in formal institutions with simultaneous lagging behind informal ones, led to a normative institutional gap. The consequences of the backwardness of the development of informal institutions were the unbalanced development of the system, the inefficiency of the functioning of formal institutions, the destruction of traditional culture, and the rapid development of the shadow economy.

Transformations of the social system, a sharp change in the priority form of ownership, the creation of new organizational corporate structures led to deep socioeconomic problems:

- loss of trust in the power and a sense of involvement in general political processes, a low level of trust between business and government has become a factor in the inefficiency of market reforms;

- the effectiveness of market reforms proved to be inadequate social and economic efficiency, which is not comparable with the paid high price in the form of deep destruction of production and technological potential, which is inadequate for the costs of other countries with economies in transition;

- the fall in the social standard of living of the population, unemployment, social insecurity became an excessively 
high price paid by the bulk of the population for the transition to capitalism. According to official figures in 2006, the average monthly income of the population was 657.31 UAH, in 2016 - $3576.9 \mathrm{UAH}$, in 2017 3632.7 UAH. The average monthly nominal wage of hired workers (43.1\% of total revenues) was: in 1995 73 UAH, in 2000 - 230 UAH, in 2002 - 376 UAH, in 2004 - $590 \mathrm{UAH}$, in 2005 - $806 \mathrm{UAH}$, in 2006 - $1041 \mathrm{UAH}$; in 2007 - $1351 \mathrm{UAH}$, in 2008 - $1806 \mathrm{UAH}$, in 2009 $1906 \mathrm{UAH}$, in $2010-2176 \mathrm{UAH}$, for the period of 2013-2017 respectively - 3234 UAH, 3476 UAH, 4195 UAH, 5070 UAH, 7104 UAH. Let's note a significant differentiation of wages by types of economic activity and regions. The inflation index for the period 2013-2018(January-June) was as follows: 100.5\%, 124.9\%, 143.3\%, 112.4\%, 113.7\%, 104.4\% (Derzhavna, 2018);

The polarization of people according to the standard of living took place and continues: $5 \%$ - rich; $80 \%-$ on the brink of poverty. According to official statistics, the quintile coefficient of funds characterizing the differentiation of the living standard of the population in 2016 was 3.0 times. The population with average per capita equivalent of a total income per month is below the actual living wage, as a percentage of the total population; in 2014-2016 it was 16.7; 51.9; 51.1.

The country has lost its competitiveness due to the growth of technical backwardness, the lack of investment resources, and the outflow of capital, which greatly worsens the international position of the country. The structure of industrial production is changing radically, with the predominant share of which is the production of commodity sectors, mainly metallurgy. The state of the technical and technological base of the economy, which annual rates of output exceed the rates of input, poses another threat to the effective development of the national economy (Kolomiiets, Golovkova, 2017).

- A sharp decline in fundamental research, underfunding of applied research and a decrease in production of science-intensive products constitute a serious obstacle to a competitive national economy. Developing countries on an innovative basis spend on science needs not less than 2.5\% of GDP. Two countries in the world South Korea and Israel - spend on research and fertility more than 4\% of GDP. According to Eurostat in 2003 and 2013, science spending in percentages of GDP is respectively: South Korea - 2.35\%, 4.15\%; EU - 3.14\%, 3.4\%; The United States - 2.55\%, 2.77\%; Japan - 1.8\%, 2.03; China - 1.13\%, 2.08\%; Ukraine - $1.06 \%$, $0.7 \%$. In 2015, this indicator in Ukraine decreased to $0.62 \%$; - reducing the volume of public investment in the real sector of the economy adversely affects the prospects for economic development. The volume and structure of such investments play an important role in the economy, influence the implementation of structural reforms, support the rapid return on capital to the region, provide the necessary level of employment;
- orienting the business to maximum profits, ignoring corporations social goals and the lack of a state position (and therefore laws and mechanisms) on the social responsibility of business led to corruption and oil, grain, sugar, gas, construction crises;

- manipulation with budgetary paintings allows reporting on filling the budget in spite of the true reality - the rapid growth of Ukraine's debts. The national debt of the country was in 2007 71,3 billion UAH. As of December 31,2017, the volume of state and stateguaranteed debt of Ukraine was 1374 995,5 UAH, out of which 1374 995,5 UAH - external debt;

- unreasonable taxation system carries out the fiscal function of filling the budget, does not ensure the implementation of the economic function (stimulation of production, cross-sectoral capital transfer);

- Ukraine accepts the position of the country of the "global periphery" in the global economy with the fulfilment of the function of providing conditions for highly developed countries;

- oligopolistic structure of markets with a high level of monopoly power;

- high level of shadowing and criminalization of many markets in which bureaucratic and criminal groups distribute commodity and financial flows through conspiracy, administrative or force pressure.

Economic reforms in Ukraine, primarily aimed at increasing the efficiency of the economy, led to the emergence of many formal institutions, both by origin and, in fact, became "formal". The practice of creating the Ukrainian formal institutions demonstrated their separation from the informal norms of the new economic order, which led to the emergence of sustainable, inefficient, really "formal" institutions. Reformed Ukrainian legislation introduced a large number of new and modified formal institutions in a short period of time. A complex system of regulation was created, the characteristics of which were: 1) the contradictory nature of certain norms to each other and informal norms; 2) the "height" of administrative barriers during the passage of bureaucratic procedures, irresistible without "obligatory" payments, do not come to the budget; 3) the selectivity of punishment, the criteria for choosing which are informal rules. This greatly complicates the orientation in formal rules for economic agents, allows the use and interpretation of contradictions in their own interests and creates the ground for the use of informal illegal rules. Unequal conditions of competition as a result of the functioning of the Ukrainian regulatory system are becoming a serious obstacle to the country's socio-economic development.

The Ukrainian economy demonstrates the opposite institutional deformation. Forced creation of new organizational structures and new private-property relations was not accompanied by the formation of adequate enforcement mechanisms for the execution of contracts. The absence of formal institutions for 
contract enforcement, reinforced by the lack of informal business culture, causes a low culture of contracts, nonfulfilment of obligations.

The massive import of market institutions was dictated by the desire to accelerate Ukraine's global integration, deepened institutional discontinuities, strengthening the state and business inclination towards opportunism. The propensity of domestic business to opportunistic behaviour and informal contracts increases institutional structural market deformities and transformational risks of the national economy. The imbalance in the development of the institutional environment raises the danger of the possibility of shadow structuring and criminalization of economic life.

In the context of systemic transformations, society has two options for development: to reject new institutions or to slowly adapt to them. The contradiction between informal and formal rules is settled in two scenarios: according to the first, one of the rules survives; for others - it is determined the possibility of embedding a formal rule in a network of informal ones. Informal rules can change indirectly through the introduction of a new system of formal rules or spontaneously. Evolutionary development of the system by a small increase in informal rules ensures the spontaneous crystallization of a small part of informal constraints as conditions for maintaining the stability and development of complexly organized systems (Shastitko, 2002).

The transformation of the spontaneous behaviour of the subjects into the modelled one is connected with the gradual replacement of ineffective informal institutions by legitimate norms on the basis of synchronization of the elements of the institutional field (Tkach, Radieva, 2014). The process of adapting economic agents to unpleasant institutional changes is ensured by new quasi-market institutions, mostly informal ones. Quasimarket mechanisms include the predatory use of all types of resources, barter, income concealment, shadow schemes for tax evasion, offshore, "under-the-counter" wages, raiding, corruption at all levels of government, widespread and multifaceted opportunism, breach of contracts, "budget" opportunism and the like. Quasimarket relations create an institutional environment that ensures the selection and updating of basic institutions aimed at strengthening the deformations of the economy.

The failure to take into account the specifics of the functioning of the institutional environment in the formation of Ukrainian corporations has led to institutional discontinuities. In developed countries, the formation and consolidation of institutional forms of economic integration were carried out through their historical development in concrete material conditions.

The corporate governance model created by the results of compulsory corporatization of state-owned enterprises was focused on achieving short-term personal gain, rather than creating effective institutional integration forms. The consequence of institutional gaps has been the emergence of stable, ineffective formal institutions and informal quasi-market institutions that have ensured the adaptation of economic agents to unacceptable institutional shifts.

The consequence of a sustained institutional disruption was the imbalance in the development of the institutional system. The dynamics of the institutional environment demonstrates outstripping the development of the formal subsystem over the informal, which generates destabilizing processes, such as the development of the informal economy. Institutional changes led to an increase in transaction costs, in the administrative economy usually paid for by the state. As a result of the combined effect of these factors, a systemic crisis occurs, during which the efficiency of production is reduced.

\section{Conclusions}

Institutional dynamics is the result of the functioning of a specific national institutional environment, shaped under the influence of political, ideological, economic, national-historical factors, essential values, ethnic characteristics and characteristics of the nation's mentality, shaped by long-term cultural influence and as a result of social interaction.

The failure to take into account the specifics of the national institutional environment, such as collectivism, motivation to achieve short-term goals, ineffective development incentives, the Orthodox spiritual priority over the mundane, communal environment, traditionalist values led to institutional disruptions in the formation of Ukrainian companies. The unbalanced development of the formal and informal components of the institutional environment has generated the main two types of normative institutional discontinuities. The rapid development of the formal subsystem over the informal led to destructive processes in the economy, such as the informal nature of economic relations with the growth of transaction costs, the destruction of traditional culture, the indignation of the household, the shadow economy and criminality; and the redistributive nature of the economy with the transition to a distributing economy with quasi-market mechanisms. Forced creation of new corporate structures and private-property relations, supported by a massive import of market institutions in the absence of adequate national formal institutions and informal corporate culture, led to non-fulfilment of contracts, low business culture, opportunistic behaviour and informal contracts. Invented in the process of adaptation of economic agents to institutional changes of quasi-urban mechanisms, such as the predatory use of all types of resources, barter, concealment of income, shadow schemes of tax evasion, offshore, "under-thecounter" wages, raiding, corruption at all levels of government, and the multifacetedness of opportunism, the violation of contracts, the consumption of fixed 
assets, strengthened the structural deformations of the market and the transformational risks of the national economy.

The development of the corporate economy on an innovative basis under the influence of globalization and monopolization changes the individual institutions of basic B-and X-matrices. A new concept of building an institutional matrix based on the distribution of the economy on the corporate and individual sectors is proposed. Two types of institutionalmatrices - corporate $\mathrm{K}$-matrices and individual I-matrices - function in basic $\mathrm{X}$ and $\mathrm{Y}$ matrices, dividing each of the economies into two unequal parts (in terms of effectiveness, influence and significance of consequences). Corporate transformations make separate complementary institutions of the market economy into the basic institutions of the corporate part of the B-economy. Continuing institutional displacement requires finding the optimal balance between basic and complementary institutions in the corporate and unincorporated sectors of the Ukrainian economy, based on the use of specific institutional matrices, which will allow for institutional construction and minimize the social costs of the country's evolutionary development. The creation of an effective institutional environment will be ensured through the cultivation of institutional changes.

\section{References:}

Bessonova, O. (2017). Formirovanie novoy realnosti: ot kvazirynka k kontraktnomu razdatku [Forming a new reality: from quasi-market to contract distribution]. Voprosy ekonomiki, 7, 96-113. (in Russian)

Derzhavna sluzhba statystyky Ukrajiny (2018). Dyferenciacija zhyttjevogho rivnja naselennja [Differentiation of the living standard of the population]. Retrieved from: http://www.ukrstat.gov.ua/operativ/operativ2007/gdvdg_rik/ dvdg_u/duferen2010_u.htm (accessed 10 June 2018) (in Ukrainian)

Donchenko, O. (2013). Instytucionaljni matryci jak struktury kolektyvnoji psykhiky [Institutional matrices as structures of the collective psyche]. Ukrajinsjkyj centr politychnogho menedzhmentu. Retrieved from: http://www.politik.org.ua/vid/magcontent.php3?m=6\&n=84\&c=2056 (accessed 16 October 2013) (in Ukrainian) Galbraith, J. (1952). American Capitalism: the Concept of Countervailing Power. Boston: Houghton Mifflin.

Kirdina-Chandler, S. (2017). Institutional Matrices Theory, or X- and Y-Theory: a Response to F. Gregory Hayden. Journal of Economic Issues, 51:2, 476-485.

Kolomiiets, V., Golovkova, L. (2017). The institutional content of the human capital of the national economy. Baltic Journal of Economic Studies, 3(5), 289-283. doi: 10.30525/2256-0742/2017-3-5-289-293

North, Douglass (1990). Institutions, Institutional Change and Economic Performance. Cambridge University Press.

Polanyi, K. (2001). The Great Transformation: The Political and Economic Origins of Our Time. (2nd ed.). Foreword by Joseph E. Stiglitz. Boston: Beacon Press.

Radieva, M. (2018). Institutional basis of corporate economy. In Yu. V. Pasichnyk (Ed.), Sozioökonomische und rechtliche Faktoren der sozialen Entwicklung unter den Bedingungen der Globalisierung (B. 1, pp. 128-144). Steyr: Shioda.

Schumpeter, J. (1989). Essays on entrepreneurs, innovations, business cycles, and the evolution of capitalism; ed. by Richard V. Clemence; with a new introduction by Richard Swedberg. Transactions Publishers.

Shastitko, A. (2016). Vybor diskretnykh institutsionalnykh alternativ: chto s chem sravnivaem [The choice of discrete institutional alternatives: what to compare with]. Obshchestvennye nauki $i$ sovremennost, 4, $134-145$. (in Russian)

Tkach, A. A., Radeva, M. N. (2014). Bazisnye instituty ekonomiki v usloviyakh transformatsii [Basic institutes of economy in conditions of transformation]. Melitopol: Kolor Print. (in Russian) 